\title{
Bond strength of modern self-adhesive resin cements to human dentin and different $\mathrm{CAD} / \mathrm{CAM}$ ceramics
}

\author{
ANDRZEJ MAŁYSA ${ }^{1}$, JOANNA WeŻGOWIEC ${ }^{1 *}$, DARIUSZ DANEL ${ }^{2}$, \\ KLAUS BOENING ${ }^{3}$, KATARZYNA WALCZAK ${ }^{3}$, MIESZKO WIĘCKIEWICZ ${ }^{1}$ \\ ${ }^{1}$ Department of Experimental Dentistry, Faculty of Dentistry, \\ Wroclaw Medical University, Wrocław, Poland. \\ ${ }^{2}$ Department of Anthropology, Ludwik Hirszfeld Institute of Immunology and Experimental Therapy, \\ Polish Academy of Sciences, Wrocław, Poland. \\ ${ }^{3}$ Department of Prosthetic Dentistry, Faculty of Medicine, \\ Dresden University of Technology, Dresden, Germany.
}

\begin{abstract}
Purpose: The aim of the study was to evaluate the shear bond strength of CAD/CAM ceramics to dentin after cementation with conventional or self-adhesive resin cements. Methods: Three self-adhesive, self-etching cements (Panavia SA, RelyX U200, Maxcem Elite), and one conventional cement (Panavia V5), were selected to lute three CAD/CAM ceramics (IPS Empress CAD, IPS e.max CAD, IPS e.max ZirCAD) onto the dentin. The bond strength was evaluated using a shear strength test according to the PN-EN ISO 29022:2013-10. Evaluation of the differences was performed using the Statistica software. Failure modes were analyzed using a light microscope. Results: All the studied cements differed (regardless of the ceramic type) in the bond strength. The highest bond strength was observed in Panavia V5, lower - in RelyX U200 and Panavia SA, and the lowest - in Maxcem. For IPS e.max ZirCAD, it was observed that compared to Panavia V5, the other cements were characterized by a significantly higher bond strength. For the IPS Empress CAD and the IPS e.max CAD, Panavia V5 displayed the highest bond strength. For all the studied self-adhesive cements, the failure of adhesion between the cement and dentin was predominant mode. Conclusions: Significant differences were found in the shear bond strengths of the $\mathrm{CAD} / \mathrm{CAM}$ ceramics luted to dentin using tested self-adhesive and conventional cements. The bond strength depended on the combination of ceramic and cement. The IPS e.max ZirCAD had the highest bond strength to dentin after cementation with RelyX U200, while the IPS Empress CAD and IPS e.max CAD - with Panavia V5.
\end{abstract}

Key words: shear bond strength, self-adhesive resin cement, dentin, CAD/CAM ceramic, dental materials, adhesion

\section{Introduction}

A remarkable technical development in the manufacturing of dental materials allowed for the creation of restorations that almost perfectly match the natural ones in terms of both function and esthetics. For this purpose, modern prosthodontics uses computer-aided design/computer-aided manufacturing ( $\mathrm{CAD} / \mathrm{CAM})$ technology, which has several advantages, such as ease of application, minimal invasiveness, stan- dardized manufacturing process, and long-term clinical success [23].

The indirect restorative materials commonly used in $\mathrm{CAD} / \mathrm{CAM}$ technology are glass ceramics (feldspathic ceramics, mica-based ceramics, leucite- or lithium disilicate-reinforced ceramics, glass-infiltrated alumina or zirconia ceramics) and polycrystalline ceramics, such as alumina and zirconia. These are highly biocompatible and esthetic; however, taking the huge amount of load in the oral environment into account, dental restorations should be ensured to pos-

\footnotetext{
* Corresponding author: Joanna Weżgowiec, Department of Experimental Dentistry, Faculty of Dentistry, Wroclaw Medical University, ul. Krakowska 26, 50-425 Wrocław, Poland. Phone: +48 7178402 91, e-mail: joanna.wezgowiec@umed.wroc.pl

Received: December 18th, 2019

Accepted for publication: March 5th, 2020
} 
sess appropriate mechanical properties to avoid their fracture or loss of contact with dentin. For this reason, many efforts have been recently made to develop materials that are characterized by not only excellent esthetics but also high strength in addition to good bond strength to the dental substrates [2], [4], [16].

To achieve a strong bonding between the ceramic and dentin, a proper luting cement should be applied. Several types of cements are used in dentistry: zinc phosphate cement, polycarboxylate cement, glass ionomer cement, resin-modified glass ionomer cement, and resin cement [14]. Resin cements can be divided into three groups: total-etch and self-etch cements, which require to be bonded to the tooth surface; and self-adhesive resin cements. Significant technological advancements made in the manufacturing of self-adhesive self-etching resin cements have enabled achieving unprecedented speed and ease of operation [1]. The issues related to bond strength that are encountered with the newgeneration self-adhesive cements are currently investigated by many research groups [1], [5], [7], [8], [14], [21], [24]. Unfortunately, due to differences in the method, the data from these studies are hardly comparable, and therefore, it is very difficult to draw a general conclusion. As many factors influence the results of bond strength tests, including the properties of dentin, properties of ceramics and their preparation, and parameters related to testing, research methods should be designed in a more standardized way [22].

This study evaluated and compared the shear bond strengths of CAD/CAM ceramics to dentin after cementation with the modern self-adhesive resin cements following the PN-EN ISO 29022:2013-10 standard to ensure the reproducibility of the results. In addition, a complex statistical analysis was performed to evaluate the differences in the bond strengths after cementation with the conventional and modern selfadhesive self-etching cements to propose the most strong combination of $\mathrm{CAD} / \mathrm{CAM}$ ceramic and resin cement. The tested null hypothesis was that there would be no difference in the shear bond strengths between the CAD/CAM ceramics luted to dentin using the modern self-adhesive and conventional resin cements.

\section{Materials and methods}

\subsection{Materials}

A total of 144 ceramic samples in a shape of a cylinder were prepared and cemented into the dentin (12 samples for each ceramic - cement combination). Three types of ceramics (IPS Empress CAD, IPS e.max CAD, IPS e.max ZirCAD) possessing different physical and chemical properties were milled using CAD/CAM technology. For each type of ceramic, 48 cylinders were prepared and divided into four groups consisting of 12 each, depending on the type of resin cement used for cementing the ceramic onto the dentin. Three resin-based cements (Panavia SA, RelyX U200, Maxcem Elite) characterized by similar physicochemical properties and binding type (self-etching, self-adhesive) were used as study materials, while one resin-based adhesive cement (Panavia V5) was selected as a control sample. The different types of ceramics and resin cements used in this study are summarized in Table 1. Ceramics were cemented into the cylinders prepared from 53 human molars, which were freshly removed and cut into 144 plasters, in accordance with the PN-EN ISO 29022:2013-10 standard.

Table 1. CAD/CAM ceramics and resin cements used in this study

\begin{tabular}{|c|c|c|}
\hline Name & Manufacturer & Type \\
\hline \multicolumn{3}{|c|}{ CERAMICS } \\
\hline IPS Empress CAD HT A1 & Ivoclar Vivadent (Schaan, Liechtenstein) & Leucite glass \\
\hline IPS e.max CAD HT A1 & Ivoclar Vivadent (Schaan, Liechtenstein) & Lithium disilicate \\
\hline IPS e.max ZirCAD & Ivoclar Vivadent (Schaan, Liechtenstein) & Zirconia \\
\hline \multicolumn{3}{|c|}{ RESIN CEMENTS } \\
\hline Panavia V5 A1 & Kuraray Noritake (Tokyo, Japan) & Adhesive \\
\hline Panavia SA Cement Universal A1 & Kuraray Noritake (Tokyo, Japan) & Self-adhesive, self-etching \\
\hline RelyX U200 A1 & 3M ESPE (Maplewood, Minnesota, USA) & Self-adhesive, self-etching \\
\hline Maxcem Elite A1 & Kerr (Brea, California, USA) & Self-adhesive, self-etching \\
\hline
\end{tabular}




\subsection{Tooth preparation}

Immediately after the extraction procedure (Wroclaw Medical University Bioethical Committee approval No. KB-37/2018), the teeth were stored in a $10 \%$ methanol solution (CHEMPUR, Piekary Sl., Poland) at $4{ }^{\circ} \mathrm{C}$ for approximately $24 \mathrm{~h}$. The soft tissue residues were removed from the teeth using a scalpel, and their surfaces were cleaned. The preprepared teeth were sectioned using the PetroThin Thin Sectioning System with diamond cutting and water cooling features (Buehler, Lake Bluff, Illinois, USA). First, the root was cut off, and then, the crown of the teeth was cut into $3-\mathrm{mm}$ slices to reveal the healthy dentin. The slices were embedded in a transparent Villacryl $\mathrm{H}$ Plus fast-curing acrylic (Zhermack, Öhlmühle, Germany) in a silicone mold of dimensions of $35 \mathrm{~mm}$ $\times 25 \mathrm{~mm} \times 4 \mathrm{~mm}$. Before cementing, the surfaces of the samples to which the ceramic materials were intended to be attached were ground with a carborundum paper of P 400 granularity (Luna, Berno, Switzerland) under a stream of running water to obtain a flat surface.

\subsection{Ceramic samples preparation}

For each resin cement, 12 cylinders of $\mathrm{CAD} / \mathrm{CAM}$ ceramics, with a diameter of $2.38 \mathrm{~mm}$ and a height of $5 \mathrm{~mm}$, were prepared following the PN-EN ISO 29022:2013-10 standard. In the first stage, the cylinders were designed in Sirona Cerec inLAB using a silicone mold and the BlueCam Sirona Cerec scanner (Sirona, New York, USA). Then, the cylinders were milled and the dimensions of the ceramic samples were checked using $150 \mathrm{~mm}$ Limit 144550100 digital

Table 2. The parameters of crystallization process and sintering

\begin{tabular}{|l|c|c|}
\hline Furnace & $\begin{array}{c}\text { IPS e.max } \\
\text { CAD }\end{array}$ & $\begin{array}{c}\text { IPS e.max } \\
\text { ZirCAD }\end{array}$ \\
\hline Standby mode $\left[{ }^{\circ} \mathrm{C}\right]$ & $\begin{array}{c}\text { Programat } \\
\text { CS }\end{array}$ & $\begin{array}{c}\text { Programat } \\
\text { S1 }\end{array}$ \\
\hline Closing time $[\mathrm{min}]$ & 403 & 403 \\
\hline Temperature increase $\left[{ }^{\circ} \mathrm{C}\right]$ & $6: 00$ & $4: 00$ \\
\hline Holding temperature $\mathrm{T} 1\left[{ }^{\circ} \mathrm{C}\right]$ & 80 & 40 \\
\hline Holding time $\mathrm{H} 1[\mathrm{~min}]$ & $0: 10$ & 960 \\
\hline Holding temperature $\mathrm{T} 2\left[{ }^{\circ} \mathrm{C}\right]$ & 840 & - \\
\hline Holding time $\mathrm{H} 2[\mathrm{~min}]$ & $7: 00$ & - \\
\hline Vacuum on $\left[{ }^{\circ} \mathrm{C}\right]$ & 550 & 450 \\
\hline Vacuum off $\left[{ }^{\circ} \mathrm{C}\right]$ & 820 & 959 \\
\hline Long-term cooling $\left[{ }^{\circ} \mathrm{C}\right]$ & 700 & 0 \\
\hline
\end{tabular}

caliper (Limit, Wrocław, Poland). The IPS e.max CAD and IPS e.max ZirCAD samples were heat-treated in accordance with the manufacturer's instructions in the Ivoclar Vivadent Programat CS and Ivoclar Vivadent Programat S1 furnaces (Schaan, Liechtenstein). The parameters of the crystallization process and sintering for the IPS e.max CAD and IPS e.max ZirCAD ceramics are presented in Table 2.

\subsection{Cementing ceramics into dentin}

Cementation was carried out in accordance with the manufacturers' recommendations. In the case of Panavia V5 cement, both the ceramics and dentin surfaces were required to be prepared. After digestion with $37 \%$ orthophosphoric acid (3M ESPE, Maplewood, Minnesota, USA), the dentin surface was rinsed with distilled water and dried. The surfaces of the IPS Empress CAD and IPS e.max CAD ceramic samples were subjected to etching with $9 \%$ hydrofluoric acid (3M ESPE, Maplewood, Minnesota, USA) for 1 min, rinsed with distilled water, and dried with air jet, while the surface of the IPS e.max ZirCAD ceramic was sandblasted with alumina of $110-\mu \mathrm{m}$ diameter using the CoJet System (3M ESPE, Maplewood, Minnesota, USA). In the case of Panavia SA, RelyX U200, and Maxcem Elite cements, the joined surfaces should be dried. Therefore, after rinsing under a stream of distilled water, the sample surfaces were dried with compressed air.

The process of cementation was carried out under the control of the $\mathrm{FB}(\mathrm{C})$ dynamometer (Axis, Gdańsk, Poland) with a fixed compression force of $10 \mathrm{~N}$ for each sample. Firstly, resin cements were applied to both surfaces and the samples were pressed. Then, the excess resin cement was removed and cement in the joined surfaces was polymerized using an Elipar LED lamp (3M ESPE, Maplewood, Minnesota, USA) for $20 \mathrm{~s}$. Before performing the shear bond strength test, the prepared samples were stored in distilled water at $37^{\circ} \mathrm{C}$ for $24 \mathrm{~h}$.

\subsection{Evaluation of the shear bond strength between ceramic and dentin}

The laboratory shear bond strength tests were carried out using a universal testing machine (Thumler, Nurnberg, Germany). The schematic illustration of a sample subjected to shear force is presented in Fig. 1. The crosshead with a $1-\mathrm{mm} / \mathrm{min}$ speed of shear knife 
movement and a maximum force of $3000 \mathrm{~N}$ were applied in the tests in accordance with the PN-EN ISO 29022:2013-10 standard. Each of the 12 tested groups representing a ceramic-cement combination had 12 samples.

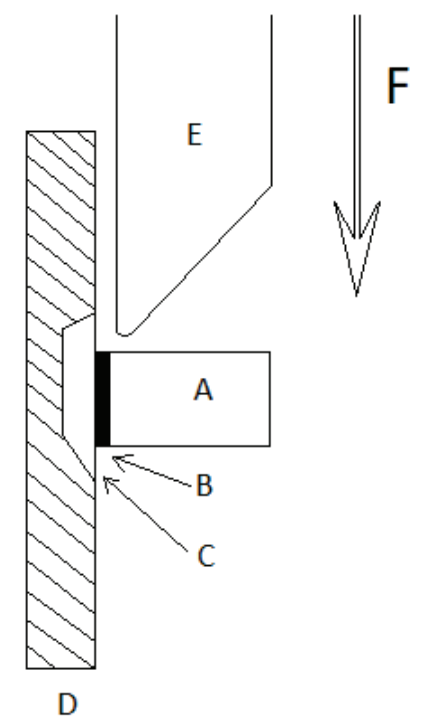

Fig. 1. Schematic illustration of a sample subjected to shear force: $A$ - ceramic cylinder, $B$ - resin cement, $C$ - slice of human tooth, $D$ - acrylic used for mounting the prepared tooth, $E$ - shear blade of the testing machine, and $F$ - direction of the applied force

\subsection{Statistical analysis}

A mixed-design analysis of variance (split-plot ANOVA) was carried out, considering ceramics (i.e., IPS e.max ZirCAD, IPS Empress CAD, IPS e.max $\mathrm{CAD})$ as a within-group repeated measure and the dental cement (i.e., Panavia SA, Panavia V5, RelyX U200, Maxcem Elite) as a between-group factor. A post hoc analysis was conducted to identify and statistically test the differences between the compared groups. Additionally, a planned contrast analysis was performed. A probability value of $p<0.05$ indicated statistically significant results. All the statistical analyses were conducted in Statistica version 13 using online tools for calculating the effect sizes as described by Lenhard and Lenhard [15].

\subsection{Analysis of failure mode under a light microscope}

The fractured specimens were observed under $\times 5$ magnification using a light microscope (Axio Lab. A1 MAT, Zeiss, Oberkochen, Germany) to determine the failure mode: failure of adhesion between ceramic and cement, failure of adhesion between dentin and cement, failure of cohesion in cement, failure of cohesion in ceramic, failure of cohesion in dentin, or mixed failure.

\section{Results}

\subsection{Evaluation of the shear bond strength between ceramic and dentin}

The results of the comparative analysis of the shear bond strength between the selected types of ceramics and dentin connected using selected resin cements are presented in Fig. 2.

All four types of dental cements examined differed (regardless of the ceramic type) in the bond strength $\left(F(3,44)=161.03, p<0.0001, \eta_{p}^{2}=0.92\right)$. The highest bond strength was observed in Panavia V5 (M = 18.02), lower - in RelyX U200 ( $\mathrm{M}=15.36)$ and Panavia SA $(\mathrm{M}=15.05)$, and the lowest - in Maxcem $(\mathrm{M}=12.40)$. The post hoc analysis by Tukey's honestly significant difference (HSD) test showed statistically significant differences (all $p_{s}<0.0002$ ) in all but one pairwise comparison of the dental cements. Only in the case of comparison between Panavia SA and RelyX U200, a statistically nonsignificant difference in the bond strength was observed ( $p=0.61$ ).

Regardless of the dental cements, the examined ceramics differed in the bond strengths $(F(2,88)=235.18$, $\left.p<0.0001, \eta_{p}^{2}=0.84\right)$. The highest bond strength was observed in IPS Empress CAD $(M=16.97)$, lower - in IPS e.max ZirCAD $(M=16.39)$, and the lowest - in IPS e.max CAD $(M=12.26)$. Tukey's post hoc tests showed that the differences observed in all the comparisons were statistically significant (IPS Empress CAD vs. IPS e.max ZirCAD: $p=0.04$; IPS Empress CAD vs. IPS e.max CAD: $p=0.0001$; IPS e.max ZirCAD vs. IPS e.max CAD: $p=0.0001$ ).

The statistically significant results observed in the analysis of the interaction between the ceramics and the resin cements $(F(6,88)=284.02, p<0.0001$, $\left.\eta_{p}^{2}=0.95\right)$ indicated that the bond strength depends on the combination of both materials (Fig. 2). While the bond strength for RelyX U200 and Panavia SA cements decreased from IPS e.max ZirCAD through IPS Empress CAD to IPS e.max CAD, a reverse pattern of results was observed for Panavia V5 (i.e., the lowest bond strength was observed for IPS e.max ZirCAD, higher - for IPS Empress CAD, and the highest - for 


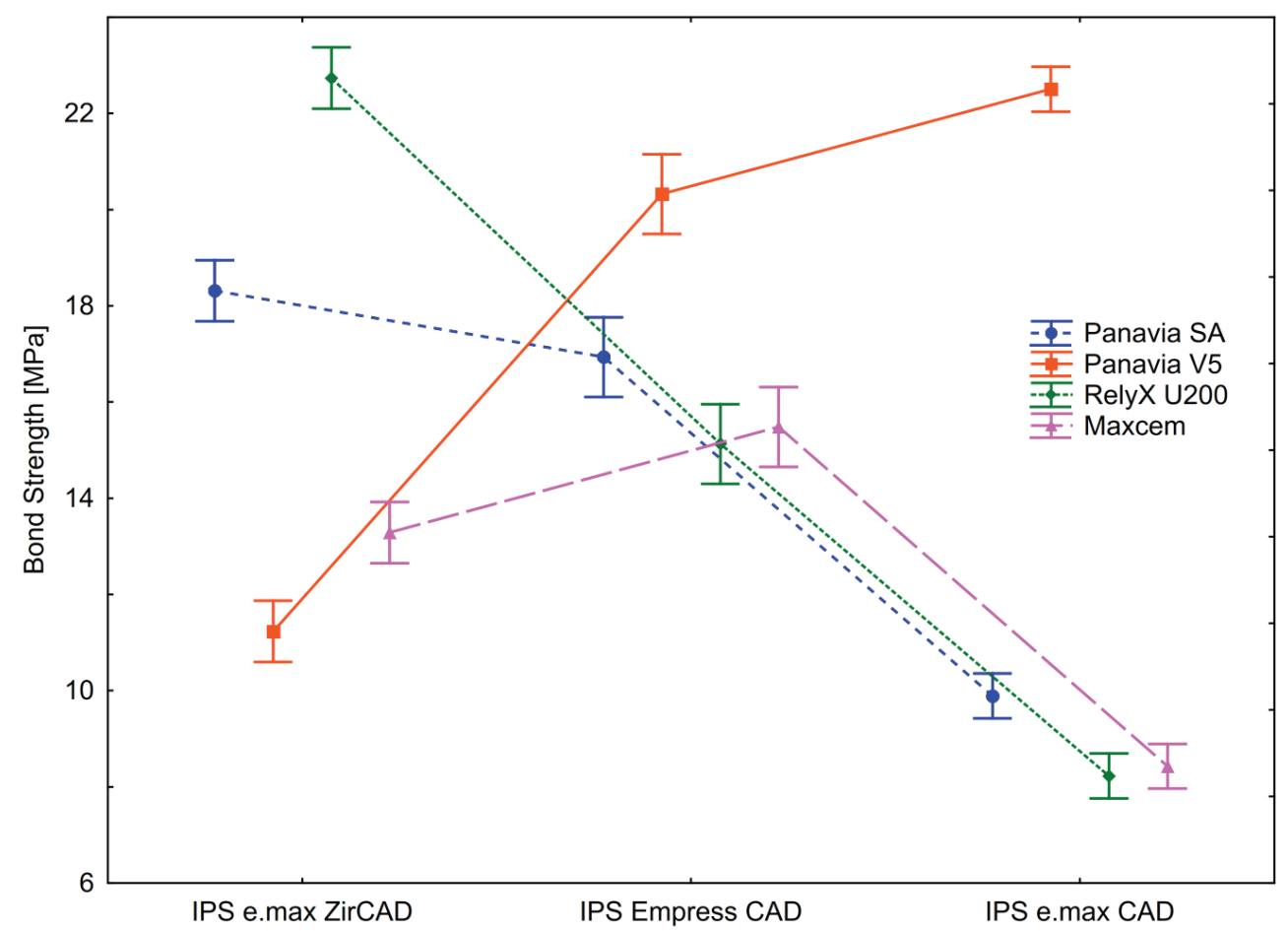

Fig. 2. Shear bond strength of the examined samples. Vertical bars denote 0.95 confidence intervals

Table 3. Planned contrast analysis of the differences in the bond strength between Panavia V5 and Panavia SA, RelyX U200, Maxcem, respectively. The Cohen's d value for groups with equal size was calculated according to the method described by Lenhard and Lenhard [15]

\begin{tabular}{|l|c|c|c|c|c|c|c|c|c|}
\hline & \multicolumn{3}{|c|}{ IPS e.max ZirCAD } & \multicolumn{3}{c|}{ IPS Empress CAD } & \multicolumn{3}{c|}{ IPS e.max CAD } \\
\hline $\begin{array}{l}\text { Panavia V5 } \\
\text { vs. }\end{array}$ & $t(44)$ & $p$ & $\begin{array}{c}\text { Cohen's } \\
d\end{array}$ & $t(44)$ & $p$ & $\begin{array}{c}\text { Cohen's } \\
d\end{array}$ & $t(44)$ & $p$ & $\begin{array}{c}\text { Cohen's } \\
d\end{array}$ \\
\hline Panavia SA & 15.85 & $<0.0001$ & 6.97 & -5.82 & $<0.0001$ & 2.78 & -38.56 & $<0.0001$ & 15.46 \\
\hline RelyX U200 & 25.75 & $<0.0001$ & 13.01 & -8.93 & $<0.0001$ & 3.49 & -43.63 & $<0.0001$ & 20.61 \\
\hline Maxcem & 4.60 & $<0.0001$ & 2.28 & -8.32 & $<0.0001$ & 4.90 & -43.02 & $<0.0001$ & 17.97 \\
\hline
\end{tabular}

IPS e.max CAD). Maxcem had the highest bond strength for IPS Empress CAD, lower - for IPS e.max ZirCAD, and the lowest - for IPS e.max CAD. The post hoc analysis by Tukey's HSD test showed that only seven (out of 66) pairwise comparisons did not show statistically significant differences, while the differences in bond strength observed in all the other comparisons were statistically significant (all $p_{s}<0.018$ ).

In order to directly test the null hypothesis, a series of planned contrast analyses were performed (detailed results are presented in Table 3). Firstly, the study focused on the IPS e.max ZirCAD samples and their bond strength to Panavia V5 was compared to that of Panavia SA, RelyX U200, and Maxcem, respectively. All the planned contrasts were statistically significant, indicating that compared to Panavia V5, the other types of resin cements examined were charac- terized by a significantly higher bond strength (in ascending order: Maxcem, Panavia SA, RelyX U200). The analogous analysis performed for the IPS Empress CAD samples also showed that all the planned contrasts were statistically significant. In this case, Panavia V5 was characterized by a significantly higher bond strength compared to the other types of resin cements (in descending order: Panavia SA, Maxcem, RelyX U200). In the last series of planned contrasts, the study focused on the IPS e.max CAD samples and their bond strength to Panavia V5 was compared to that of other types of cements. As observed in the other cases, all the planned contrasts were statistically significant. Compared to Panavia V5, all the other types of cements were characterized by a significantly lower bond strength (in descending order: Panavia SA, Maxcem, RelyX U200). 


\subsection{Analysis of failure mode under a light microscope}

Representative photographs obtained in the analysis of failure mode are presented in Figs. 3 (photographs of ceramic surfaces) and 4 (photographs of dentin surfaces), and the quantitative results are presented in Table 4. In the case of all the self-adhesive cements studied (Panavia SA, Maxcem, RelyX U200), the predominant failure mode was the failure of adhesion between the cement and dentin was. However, for Panavia V5, different modes of failure were observed for different ceramics used: for IPS e.max ZirCAD ceramic, the failure mode identified was failure of adhesion between dentin and cement or ceramic and cement; for IPS Empress CAD, the mode was failure of cohesion in cement or mixed failure; and for IPS e.max CAD, it was failure of adhesion between ceramic and cement.
IPS e.max ZirCAD

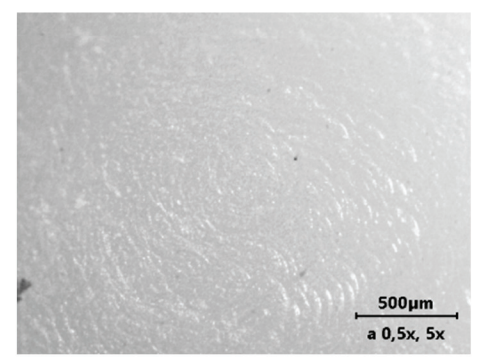

Panavia V5

Panavia SA

RelyX

U200

Maxcem

a $0,5 x, 5 x$

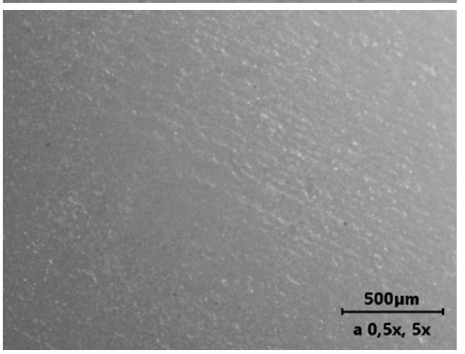

IPS Empress CAD
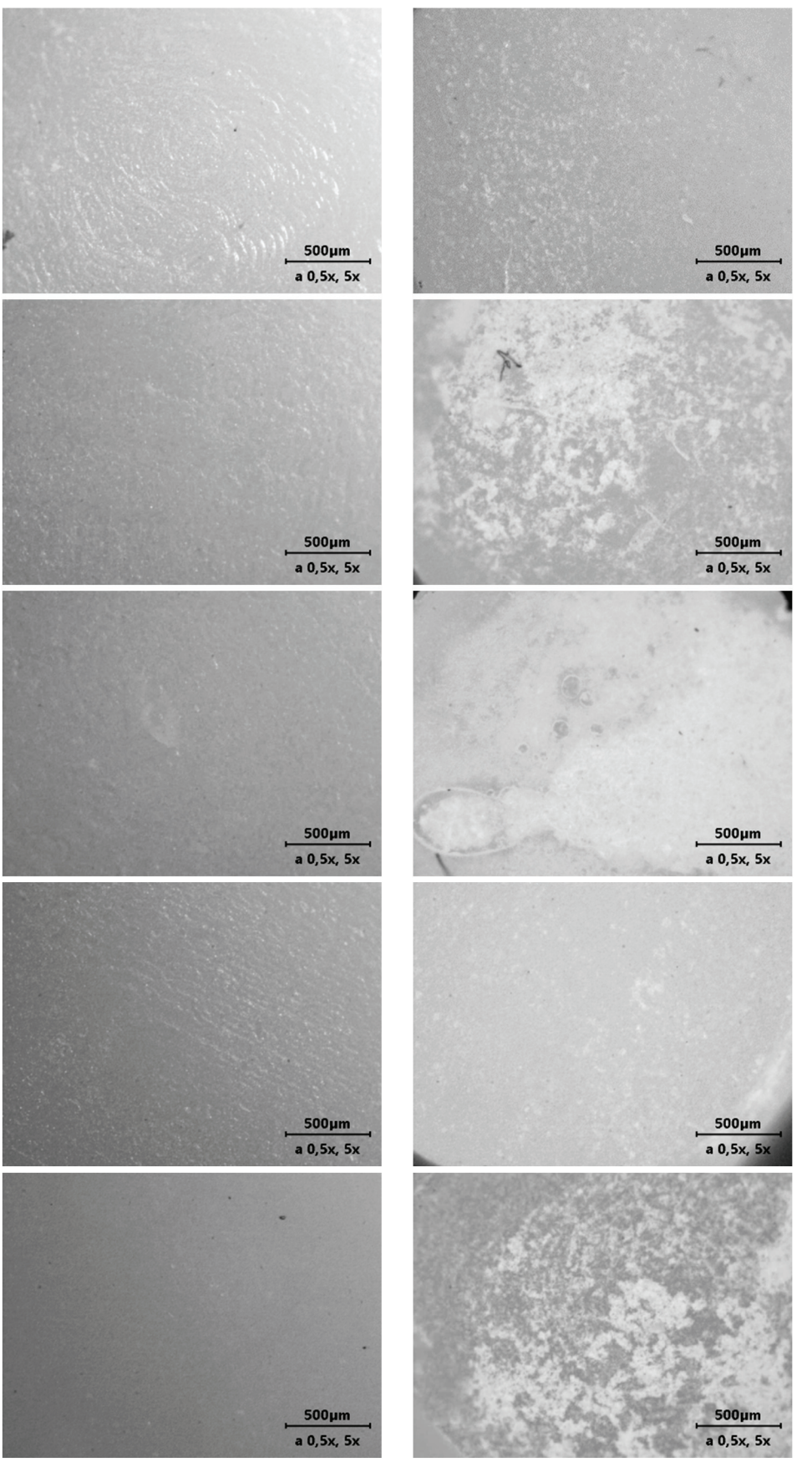
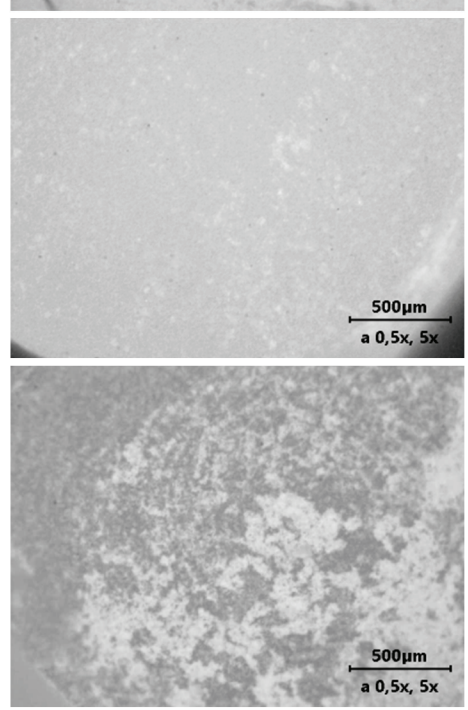

IPS e.max CAD
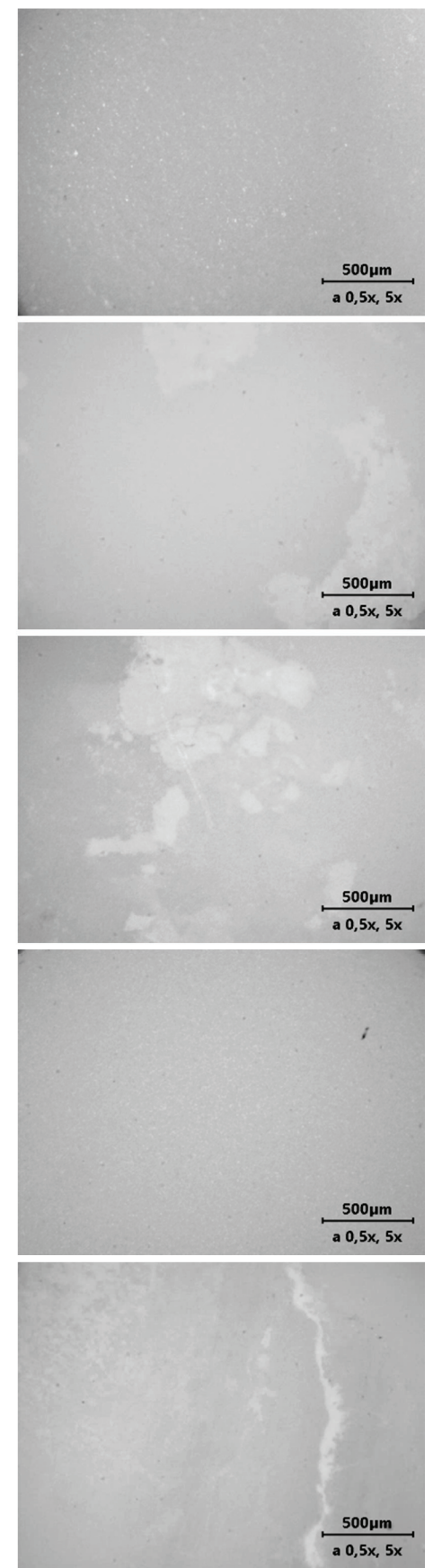

Fig. 3. Light microscope photographs of different failure modes observed on ceramic surfaces 
IPS e.max ZirCAD

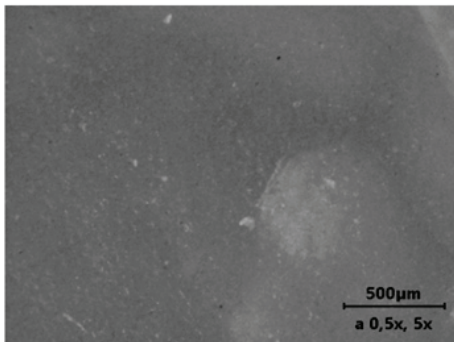

\section{Panavia SA}

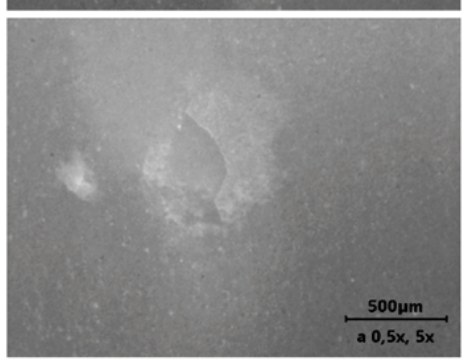

RelyX

U200

Maxcem
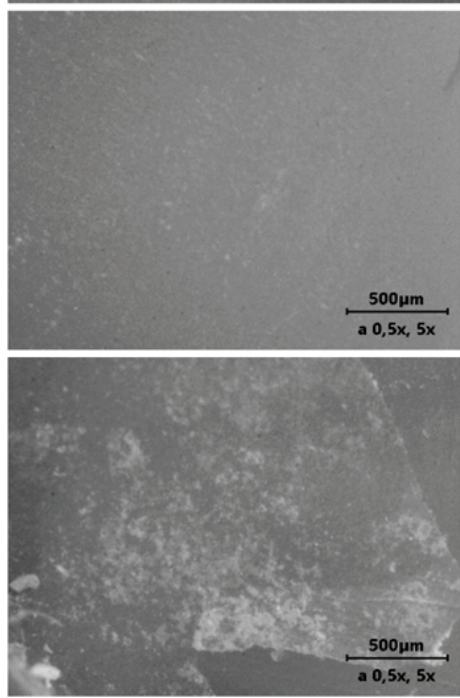

IPS Empress CAD
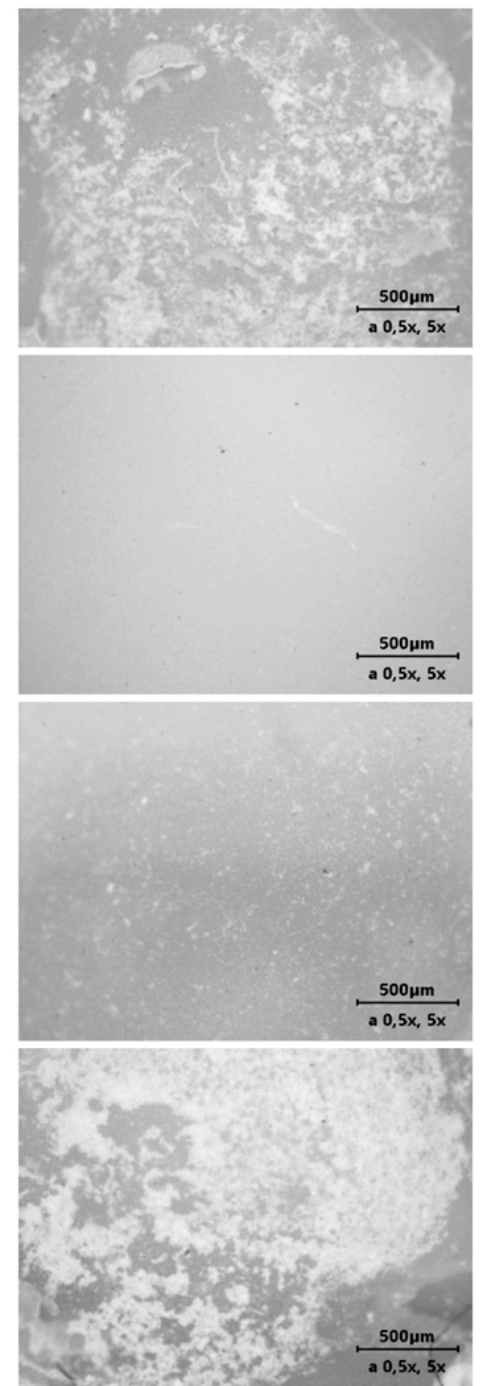

IPS e.max CAD
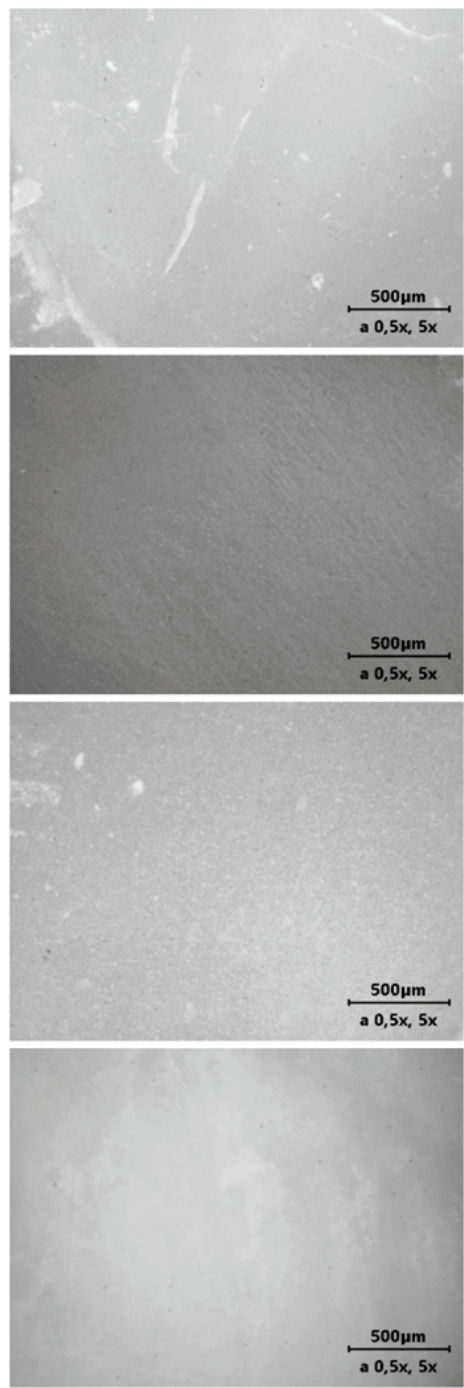

Fig. 4. Light microscope photographs of different failure modes observed on dentin surfaces

Table 4. Quantitative results of the analysis of failure mode

\begin{tabular}{|c|c|c|c|c|c|}
\hline \multirow[b]{2}{*}{ Ceramic } & \multirow[b]{2}{*}{ Resin cement } & \multicolumn{4}{|c|}{ Failure mode [\%] } \\
\hline & & $\begin{array}{c}\text { Adhesive failure } \\
\text { at dentin/cement } \\
\text { interface }\end{array}$ & $\begin{array}{l}\text { Adhesive failure } \\
\text { at ceramic/cement } \\
\text { interface }\end{array}$ & $\begin{array}{l}\text { Cohesive } \\
\text { failure } \\
\text { in cement }\end{array}$ & $\begin{array}{l}\text { Mixed } \\
\text { failure }\end{array}$ \\
\hline \multirow[t]{4}{*}{ IPS e.max ZirCAD } & Panavia V5 & 50 & 50 & 0 & 0 \\
\hline & Panavia SA & 75 & 25 & 0 & 0 \\
\hline & RelyX U200 & 100 & 0 & 0 & 0 \\
\hline & Maxcem & 91.66 & 8.34 & 0 & 0 \\
\hline \multirow[t]{4}{*}{ IPS Empress CAD } & Panavia V5 & 0 & 0 & 50 & 50 \\
\hline & Panavia SA & 83.33 & 0 & 0 & 16.67 \\
\hline & RelyX U200 & 75 & 0 & 25 & 0 \\
\hline & Maxcem & 75 & 0 & 25 & 0 \\
\hline \multirow[t]{4}{*}{ IPS e.max CAD } & Panavia V5 & 0 & 91.66 & 0 & 8.34 \\
\hline & Panavia SA & 100 & 0 & 0 & 0 \\
\hline & RelyX U200 & 83.33 & 0 & 0 & 16.67 \\
\hline & Maxcem & 91.66 & 0 & 8.34 & 0 \\
\hline
\end{tabular}




\section{Discussion}

Due to their very good biocompatibility, esthetics, and cost-effectiveness, $\mathrm{CAD} / \mathrm{CAM}$ ceramics are widely gaining attention for application in permanent prosthetic reconstructions. The clinical success of a bonded ceramic restoration strongly depends on its durable bonding to dentin, ability of optimal marginal adaptation after cementation, and overall strength [3], [12], [24].

In order to achieve a strong bonding of a ceramic material to the supporting tooth structure, it is necessary to apply an appropriate cement. The new-generation self-adhesive self-etching resin cements seem to be an ideal option for this purpose since they do not need a separate etching, priming, or bonding process, and are, therefore, easier to handle and less techniquesensitive. However, a previous study indicated that self-adhesive resin cements have a lower bonding ability compared to adhesive cements [18].

The present study revealed that, in general, ceramics cemented to dentin using the conventional Panavia V5 cement displayed a significantly higher shear bond strength than those cemented using the self-adhesive self-etching cements. Similar results were reported in the study by Ab-Ghani et al. [1], which demonstrated that the multistep etch-and-rinse adhesive bonding (Variolink II cement) of CAD/CAM ceramics to dentin was characterized by a statistically significantly higher shear bond strength than the bonding achieved using the self-adhesive cement (RelyX U200). In addition, Gundogdu et al. [8] revealed that the self-etch adhesive resin cements exhibited a higher shear bond strength than the self-adhesive resin cements. Their study was performed following the ISO/TS 11405:2003 standard, but instead of the CAD/CAM ceramics, they used two types of pressable ceramic materials (IPS e.max Press and Prettau Zirconia). The lower shear bond strength of the self-adhesive resin cements noted in the study may be explained by the fact that this type of material interacts superficially with mineralized tissue and cannot demineralize the dentin completely. Thus, the smear layer cannot be completely removed, and hence, it is impossible to achieve the full formation of resin tags in the hybrid layer [5], [13], [20], [24].

Nevertheless, in the analysis of the bonding ability of the individual cements to the individual ceramics in the current study, one of the ceramics - IPS e.max ZirCAD - was found to show the highest adhesion to dentin $(22.74 \mathrm{MPa})$ after cementation with RelyX U200 among all the cements tested, even higher than that observed after cementation with Panavia V5. In a study by Lee et al. [14], the shear bond strength of the combination of zirconia (Zirtooth, HASS, Kangneung, Korea) and RelyX U200 was reported at an average level of $2.84 \mathrm{MPa}$. Moreover, the shear bond strength measured by Lee et al. [14] for another resin cement - Maxcem Elite - was 2.86 MPa, while in the present study it was $13.29 \mathrm{MPa}$. The discrepancies in the obtained results may be due to the use of different ceramic materials and different methods for the preparation of zirconia samples.

One of the possible reasons for the differences in the measured bonding forces of the selected cements can be attributed to the different compositions of these materials. Additionally, Arango et al. [2] reported that the shear bond strength of the cements was dependent on the nature of the prosthodontic substrate. In the present study, three CAD/CAM ceramics, differing in composition and crystal structure, were studied. IPS e.max ZirCAD MO is a 3Y-TZP generation of dental zirconia (yttria-stabilized tetragonal zirconia polycrystal) which has a typical crystal size of $0.5 \mu \mathrm{m}$ and a crystal phase volume of $98 \%$ [9]. IPS e.max CAD is a glass ceramic containing lithium disilicate crystals at a volume of approximately $70 \%$ and a typical size of $1.5 \mu \mathrm{m}$ [10]. IPS Empress CAD is a leucite-reinforced glass ceramic with a crystal phase volume of $35-45 \%$ and a crystal diameter of $1-5 \mu \mathrm{m}$ [11]. In this study, it was found that, notwithstanding the dental cements, IPS Empress CAD had the highest bond strength. This observation can be explained by the biggest size of the crystals present in this material.

The analysis of failure mode revealed that in the case of all the studied ceramics luted with self-adhesive cements, the most frequently noted mode of failure was adhesive failure at the dentin/cement interface. The dentin/resin cement interface was weaker than the resin cement/ceramic interface, which corresponds to the observations described previously by the other researchers and could be explained by the limited ability of the self-adhesive cements to demineralize dentin [8], [17]-[19], [25]. In order to improve the bonding of self-adhesive resin cements to dentin, either the dentin should be properly pretreated or the chemistry of the cements should be modified [6].

The current study was performed in laboratory conditions in order to determine some basic relationships, however, the associated simplifications should be first understood. One of the limitations is related to the simplified structure of the tested samples, since only one surface of dentin was cemented, whereas in the case of crowns or bridges the restoration is cemented into five surfaces of the prepared teeth. Additionally, in further studies, some important phenomena, such as the degradation of resin cements after long periods of 
exposure to oral fluids and cyclic mechanical fatigue occurring during chewing should also be taken into account in order to simulate the clinical conditions more realistically. In a study by Sathish et al. [21], it was demonstrated that thermocycling, which was used for artificial aging, affected the bond strength of the different resin cements used. Moreover, additional physical properties, such as tensile strength and flexural strength, should be examined. Application of several methods of surface treatment, such as hydrofluoric acid etching, silanization, and treatment with adhesives or laser, that can improve the bond strength of dental restorations, is also worth investigating [3]. In the future, the preliminary results reported in this research should be verified by a clinical study evaluating the in vivo performance of the self-adhesive resin cements.

\section{Conclusions}

The present study revealed significant differences between the shear bond strengths of the CAD/CAM ceramics luted to dentin using different self-adhesive and conventional resin cements, and so the tested null hypothesis was rejected.

The following conclusions can be drawn on the basis of the obtained results:

1. Notwithstanding the dental ceramic, the examined cements differed in the bond strengths; the highest bond strength was observed in Panavia V5, lower - in RelyX U200 and Panavia SA, and the lowest - in Maxcem.

2. Similarly, notwithstanding the dental cements, the examined ceramics differed in the bond strengths; the highest bond strength was observed in IPS Empress CAD, lower - in IPS e.max ZirCAD, and the lowest - in IPS e.max CAD.

3. The bond strength depends on the combination of ceramic and cement. IPS e.max ZirCAD displayed the highest bond strength to dentin after cementation with RelyX U200, while IPS Empress CAD and IPS e.max CAD showed the highest strength after cementation with Panavia V5.

4. In the case of all the studied self-adhesive cements (Panavia SA, Maxcem, RelyX U200), the predominant mode of failure observed was the failure of adhesion between the cement and dentin.

\section{Acknowledgements}

This study was supported by Funds of Wroclaw Medical University (No. ST.B.160.18.025).
The authors would like to thank Mrs. Anna Biernacka from Hager Polonia Company for providing the Panavia resin cements.

\section{References}

[1] Ab-Ghani Z., Ariffin Z., JaAfar W., Foo S., Mohamad D., Shear bond strength of computer-aided design and computeraided manufacturing feldspathic and nano resin ceramics blocks cemented with three different generations of resin cement, J. Conserv. Dent., 2015, 18, 355.

[2] Arango S., Pelaez Vargas A., Monteiro F.J., Tamayo L.F., Ceramics for Dental Restorations - An Introduction, Dyna (Columbia), 2010, 163, 26-36.

[3] Barutcigil K., Barutcigil Ç., Kul E., Özarslan M.M., BUYUKKAPLAN U.S., Effect of different surface treatments on bond strength of resin cement to a CAD/CAM restorative material, J. Prosthodont., 2019, 28, 71-78.

[4] Blatz M.B., Vonderheide M., CONEJO J., The Effect of Resin Bonding on Long-Term Success of High-Strength Ceramics, J. Dent. Res., 2018, 97, 132-139.

[5] Dalby R., Ellakwa A., Millar B., Martin F.E., Influence of immediate dentin sealing on the shear bond strength of pressed ceramic luted to dentin with self-etch resin cement, Intern. J. of Dent., 2012, 310702.

[6] Fuentes M.V., Ceballos L., González-López S., Bond strength of self-adhesive resin cements to different treated indirect composites, Clin. Oral Investig., 2013, 17, 717-724.

[7] Go E., SHIN Y., PARK J., Evaluation of the microshear bond strength of MDP-containing and non-MDP-containing self-adhesive resin cement on zirconia restoration, Oper. Dent., 2019, 44, 379-385.

[8] Gundogdu M., Aladag L.I., Effect of adhesive resin cements on bond strength of ceramic core materials to dentin, Niger J. Clin. Pract., 2018, 21, 367-374.

[9] IvoclarVivadent Official: https://www.ivoclarvivadent.pl/pl/ $\mathrm{p} /$ dla-technikow-dentystycznych/produkty/materialy-caloceramiczne/ ips-emax-system-dla-technikow/ips-emax-zircad/, [accessed: 12 November 2019].

[10] IvoclarVivadent Official: https://www.ivoclarvivadent.pl/pl/ p/dla-technikow-dentystycznych/ips-emax-cad-mt/, [accessed: 12 November 2019.

[11] IvoclarVivadent Official: https://www.ivoclarvivadent.pl/pl/ $\mathrm{p} /$ dla-technikow-dentystycznych/produkty/materialy-caloceramiczne/ips-empress-system-dla-technikow/ips-empress-cad/, [accessed: 12 November 2019].

[12] Kachhara S., ARIGa P., JaIN A., Recommended cementation for monolithic zirconia crowns, Drug Invent. Today, 2018, 10, 566-568.

[13] LeE J.J., ChOI J.Y., Seo J.M., Influence of nano-structured alumina coating on shear bond strength between Y-TZP ceramic and various dual-cured resin cements, J. Adv. Prosthodont., 2017, 9, 130.

[14] Lee S., Bae J., Choi J., Jeon Y., Jeong C., Yoon M., Huh J., Comparative Shear-Bond Strength of Six Dental Self-Adhesive Resin Cements to Zirconia, Materials, 2015, 8, 3306-3315.

[15] Lenhard W., LenHard A., Calculation of effect sizes, Psychometrica, Dettelbach, Germany, 2016.

[16] Li R.W.K., Chow T.W., Matinlinna J.P., Ceramic dental biomaterials and CAD/CAM technology: State of the art, Journal of Prosthodontic Research, 2014, 58, 208-216. 
[17] Lührs A.K., Guhr S., Gunay H., Geurtsen W., Shear bond strength of self-adhesive resins compared to resin cements with etch and rinse adhesives to enamel and dentin in vitro, Clin. Oral Investig., 2010, 14, 193-199.

[18] Ozyoney G., YanikoĞLu F., TaĞTekin D., Ozyoney N., OKsüz M., Shear Bond Strength of Composite Resin Cements to Ceramics, Marmara Dent. J., 2013, 2, 61-66.

[19] Peutzfeldt A., SAhafi A., Flury S., Bonding of restorative materials to dentin with various luting agents, Oper. Dent., 2011, 36, 266-273.

[20] Rebholz-Zaribaf N., ÖZcan M., Adhesion to zirconia as a function of primers/silane coupling agents, luting cement types, aging and test methods, J Adhes Sci Technol, 2017, 31, 1408-1421.

[21] Sathish S., Lakshmi S., Patel P., AnNapoorni H., Effect of thermocycling on the micro-tensile bond strength between self-adhesive resin cement and nonphosphate monomer cements on zirconium-oxide ceramics, Indian J. Dent. Res., 2019, 30, 73-79.

[22] Sirisha K., Rambabu T., Ravi Shankar Y., Ravikumar P., Validity of bond strength tests: A critical review, Part I, J. Conser. Dentis., 2014, 17, 305-311.

[23] Spitznagel F.A., Boldt J., Gierthmuehlen P.C., CAD/CAM Ceramic Restorative Materials for Natural Teeth, J. Dent. Res., 2018, 97, 1082-1091.

[24] Suyama Y., De Munck J., Cardoso M.V., Yamada T., VAN MEERBEEK B., Bond durability of self-adhesive composite cements to dentine, J. Dent., 2013, 41, 908-917.

[25] Viotti R.G., Kasaz A., Pena C.E., Alexandre R.S., ARRAIS C.A., REIS A.F., Microtensile bond strength of new self-adhesive luting agents and conventional multistep systems, J. Prosthet. Dent., 2009, 102, 306-312. 